\title{
The Level of Metacognitive Thinking Among Students with Learning Disabilities
}

\author{
Mohamad Khasawneh ${ }^{1}$, Mohammad Alkhawaldeh ${ }^{1} \&$ Fadi Al-Khasawneh $^{2}$ \\ ${ }^{1}$ Department of Special Education, Faculty of Education, King Khalid University, Saudi Arabia \\ ${ }^{2}$ Department of English Language, Faculty of Languages and Translation, King Khalid University, Saudi Arabia \\ Correspondence: Fadi Al-Khasawneh, King Khalid University, P. O. Box 960, Asir - Abha, Saudi Arabia, 61421. \\ E-mail: khasawneh83@yahoo.co.uk
}

Received: May 5, 2020 Accepted: June 7, $2020 \quad$ Online Published: August 19, 2020

doi:10.5539/ijel.v10n5p343 URL: https://doi.org/10.5539/ijel.v10n5p343

\begin{abstract}
The present study aims at identifying the level of metacognitive thinking among a group of students with learning disabilities (LDs) in Asir region, Saudi Arabia. The present study has taken into account certain variables when investigating this issue such as age, grade, and type of learning difficulties. The sample of this study consisted of 350 students with learning disabilities from schools belong to the Department of Education in Asir Area, Saudi Arabia. To achieve the goal of the study, a scale prepared by the authors was used to measure the level of metacognitive thinking among the students. The results of the study showed that the students had a low level of metacognitive knowledge. The results have also showed no statistically significant differences in the level of metacognitive thinking attributed to age, gender, and the type of learning disability. Based on the results obtained in the present study, some suggestions and recommendations have been provided for further research on this field.
\end{abstract}

Keywords: metacognition, metacognitive thinking, students with learning disabilities, Asir region

\section{Introduction}

People with learning disabilities (LD) are a heterogeneous group in terms of intelligence, age or achievement at the level of school subjects. In terms of intelligence, we find some with average intelligence and others above average, which means that they have mental abilities to help them learn what their regular peers are learning, but with some necessary adjustments in the teaching methods used in their learning. In terms of the level of their achievement in specific subjects, the situation is different, where some students have difficulties in reading and writing while others have difficulty in mathematics. Therefore, the methods used for students with learning disabilities should be reconsidered by adopting sound scientific thinking, away from memorization and indoctrination or in the programming of minds, in order to cope with the accelerated progress and to simulate the future. In addition, there must be a shift from traditional educational tools to focus on strategies of learning and thinking in all its innovative, creative and critical forms, and to transform it into a knowledge in the form of recognizing and discovering relationships and phenomena that enable the students to move from the knowledge stage to a metacognition stage; i.e., thinking about thinking (Faramawi \& Hassan, 2004). Knowledge is defined as being able to plan and recognize the actions and techniques we follow in order solve problems, in addition to the competency of evaluating the effectiveness of thinking (Farhan, 2003). Moreover, within educational environments, attention should be paid to the skills of metacognition of students to have significant results on the development of the different kinds of cognitive thinking, which will be reflected on their learning and will accelerate their learning.

\subsection{Statement of the Problem}

The problem of the study stemmed from a review of previous studies and the literature on metacognitive thinking of people with learning disabilities. The literature showed that there is a great importance for the awareness among students with LDs. This awareness involves thinking beyond knowledge and that such awareness and ability to know their feelings contribute to their understanding of themselves. It also plays a vital role in their cognitive ability and organization, planning, and optimal access to solutions to the problems and situations they face, and thus acquiring access to a high level of performance and achievement. 
Few studies, to the best knowledge of the researchers, have tackled the level of metacognitive thinking among people with learning disabilities at the Saudi context. Moreover, due to the importance of this topic to the reality of the educational process and the inputs provided to the labor market, this study came to shed light on the level of metacognitive thinking of a sample of students with LD in Asir Area. The study of metacognitive thinking among students with LD could be useful to the educational process in general and achievement of students in particular. This study specifically sought to answer the following questions:

1) What is the level of metacognitive thinking among students with learning disabilities in Asir Area?

2) Does the level of metacognitive thinking among students with learning disabilities differ according to age, gender, and type of difficulty?

\subsection{Significance of the Study}

Studying the different types of thinking is a major goal for educators because of its importance in developing the various aspects in the learner's personality. The significance of this study stems from the scarcity of Arabic studies on this field -to the best knowledge of the researchers-, especially in the Saudi environment, which dealt with measuring the level of metacognitive thinking among students with learning disabilities. The results obtained from this study could be of great help and importance to educators. If the level of metacognitive thinking is low among students with learning disabilities, educators should reconsider the educational process and its associated curricula, courses, methods of teaching, and the use of activities accompanying the curriculum, which helps in the development of thinking beyond knowledge. Teachers also should use teaching methods that help them develop metacognitive thinking of their students with learning disabilities, which will be reflected positively in their performance when facing the difficulties they have in their lives and studies, and eventually achieving desired objectives. High levels of metacognitive thinking may support the process of increasing the educational achievement of students with learning disabilities. This high level can be utilized in all spheres of life, whether academic or social. This study will also help in building a scale for measuring the level of metacognitive thinking based on a scientific and systematic basis, thus creating room for researchers to make use of it in different research fields, locally and in the Arab world.

\subsection{Limitations of the Study}

This study was limited to a certain sample of students; this sample is a group of LDs students in Asir Area during the first semester of the academic year 2017-2018. The sample was selected based on their convenience and this means that the researchers have used convenient sampling method. The study included only students with learning disabilities and no other students have been involved.

\section{Literature Review}

\subsection{Metacognitive Thinking}

Metacognitive thinking is the individual's self-awareness of his/her cognitive processes and cognitive structure and using this awareness in the management of these processes and skills, such as planning, observing, evaluation, decision-making, and selection of appropriate strategies. The term metacognition was first coined by John Flavell in the late 1970s to mean "cognition about cognitive phenomena," or "thinking about thinking" (Flavell, 1979). Other researchers in the field provided other definitions for metacognition. One definition for example specified that it is "the knowledge and control children have over their own thinking and learning activities" (Cross \& Paris, 1988). Another definition stated that it is the "awareness of one's own thinking, awareness of the content of one's conceptions, an active monitoring of one's cognitive processes, an attempt to regulate one's cognitive processes in relationship to further learning, and an application of a set of heuristics as an effective device for helping people organize their methods of attack on problems in general" (Hennessey, 1999).

There is consensus in the literature that knowledge about cognition and monitoring of cognition are two major components of metacognition (Flavell, 1979). Many scholars in this field developed frameworks for this concept to facilitate its usage and understanding. For example, the concepts of declarative and procedural knowledge were used to differentiate the various cognitive knowledge types (Schraw \& Moshman, 1995). The second element of metacognition, monitoring of cognition, is a very important component for the individual, as it includes activities of planning, monitoring or regulating, and evaluating (Paris \& Winograd, 1990). Therefore, it is important to link these theories to any measurement of the levels of metacognition of students, especially students with LD. For the purpose of this study, metacognition is defined procedurally as the response of students with learning disabilities to the paragraphs of the scale that was prepared by the researchers and calculated through the total score obtained the sample on the metacognitive thinking scale. 


\subsection{Students with Learning Disabilities}

LD students show disorders in one or more of the basic psychological processes that include understanding of written or spoken language and their usage, which appear in hearing, thinking, speech, reading, spelling, and arithmetic disorders and are contributed to reasons related to simple functional brain malfunction, but not to causes related to mental, auditory, visual or other disabilities (Khasawneh, 2016). The metacognitive knowledge among students with LD have been investigated by many studies that showed different levels and results. In general, students with learning disabilities showed difficulties in thinking about their thoughts (Wiens, 1983). They also showed a deficit in their self-knowledge that leads to difficulties in learning (Vaidya, 1999). However, for the purpose of this study, students with learning disabilities are those students officially diagnosed by the Ministry of Education of having learning disabilities and are enrolled in learning difficulties rooms in the schools of the Department of Education in Asir Area.

\subsection{Previous Studies}

The literature on education describes different levels of meta-cognition thinking among learning disability students. The following is a review of some of the available studies related to this topic locally and internationally. In the context of Saudi Arabia, one study conducted to identify the impact of using Metacognitive Strategies to improve students' reading skills in the Northern Borders Areas in Saudi Arabia. The study was applied to a sample of 65 students in elementary levels, who were assigned to two groups; 35 each. After applying the metacognitive strategy on the experimental group, the study revealed significant results in the improvements of skills among students with learning disabilities and thus support the use of such strategies in education (Alenizi \& Alanazi, 2016). Also in Saudi Arabia, another study examined the improvement of reading comprehension among deaf and hard of hearing $(\mathrm{DHH})$ in higher education by using metacognitive strategies that use digital books. The sample of the study $(n=72)$ was assigned to two groups; a control group, who was taught by metacognitive printed materials, and an experimental group, who was taught using metacognitive digital books. The findings of the study showed significant improvement for both groups in the skills of reading comprehension, with the experimental group having higher scores (Alsalem, 2018).

In Turkey, one study investigated the impact of using the levels of metacognitive reading strategies by students with specific learning disability (SLD), academic self-efficacy and the concept of self, as compared to their typically developing (TD) peers. The study was conducted on a sample of 119 students (59 with SLD and 60 with TD). The results showed that students with SLD were significantly inadequate compared to TD students in their usage of levels of metacognitive reading strategies and the levels of academic self-efficacy (Özturk, 2017). Another study investigated the effect of the strategy of thinking maps on the development of the metacognitive knowledge and skills achievement in science among primary school students. The study sample consisted of 70 students from the sixth grade. The results of the study showed that the effect size of thinking maps on the development of cognitive and metacognitive knowledge achievement among students in the experimental group was very large (Abu Issa, 2016). In Iran, one study conducted to explore the effect of a game-based intervention on the metacognitive, behavioural and functional skills among students with LD. The study used the experimental design and applied on (49) students, divided into two groups, experimental and control. The experimental group received a game-based intervention and the results revealed the impact of such an intervention on developing metacognitive and behavioural skills (Esmaili, Shafaroodi, Mehraban, Zarei, \& Akbari-Zardkhaneh, 2017).

A Kuwaiti study conducted to identify the effectiveness of a training program based on cognitive development of the meta-cognitive strategies using the method of problem-solving to increase the educational achievement of fifth-grade students with learning disabilities in the primary stage. The study applied the program on the experimental group for one month to include 20 sessions in total. The results showed that the proposed training program was effective in increasing the academic achievement in mathematics and Arabic for students with learning disabilities (Al-Dokhi, Al-Yousif, \& Al-Atara, 2016). In a systemic review on the effectiveness of working memory among LD students, different studies have been reviewed and a meta-analysis was conducted to investigate the effectiveness of programs in this field. The study reviewed 13 randomly selected studies. The result showed a short-term improvement in working memory, spatial-working memory, and coding of words for learning disabilities students after training. These improvements continued for about eight months. The results also showed that children over the age of 10 benefited from verbal working memory more than students who are younger (Hendriksen, Vles, Aldenkamp, Hurks, \& Peijnenborgh, 2017).

Another systematic review conducted to compare the academic, cognitive, and behavioral performance of children with and without reading disabilities and to identify the effect size of these studies. Forty-eight studies met the criteria of selection. The results of the review supported the assumption that deficits in children with RD are 
persistent (Kudo, Lussier, \& Swanson, 2015). These studies were conducted in different countries and no studies, to the best knowledge of the researchers, have been conducted on the metacognition of LD students in Saudi Arabia. Therefore, this study aimed to fill the gap by identifying the level of metacognitive skills among a sample of students with learning disabilities in Asir Area, Saudi Arabia.

\section{Methods}

\subsection{Population and Sample}

The population of the study consisted of 350 students enrolled in special education classrooms in schools of the Department of Education in the Asir Area in primary grades: 3, 4, 5 and 6, which was the same number chosen to be the study sample. The researchers distributed 350 questionnaires to measure the level of metacognitive thinking and the data were filled in with the help of learning difficulties teacher, Arabic language teacher and physical education teacher, which was because of the difficulties of reading and writing among the student. Table 1 shows the sample distribution by age, grade and type of difficulty.

Table 1. Distribution of study sample by age, grade and type of difficulty

\begin{tabular}{lll}
\hline & Year & Number \\
\hline Age & 8 & 56 \\
& 9 & 102 \\
& 10 & 109 \\
Grade & 11 & 83 \\
& third & 56 \\
& fourth & 102 \\
Type of difficulty & fifth & 109 \\
& sixth & 83 \\
& reading & 145 \\
& writing & 180 \\
& account & 25 \\
\hline
\end{tabular}

\subsection{Instrumentation}

The researchers developed a questionnaire to identify the existence of metacognitive thinking among students with LD in Asir Area after reviewing theoretical literature on metacognitive thinking and relevant previous Arab and foreign studies. The researchers conducted an exploratory study that included a question for teachers in Asir Area. The question was "What are the most important practices observed on learning disabilities students that indicate their use of metacognitive thinking?" In this exploratory question, the answers were used to choose the appropriate paragraphs for the questionnaire. The dimensions and paragraphs of the questionnaire have been developed accordingly, and the questionnaire consisted in its final form of 28 paragraphs.

\subsection{Validity of the Scale}

The validity of the scale has been done first by sending the questionnaire to ten experienced and competent judges, who are faculty members at King Khalid University, Jeddah University and the Hashemite University. The researchers adopted a consensus of $80 \%$ of the judges as a criterion for the acceptance of the paragraphs of the scale, which means that the observations of more than $20 \%$ was a sufficient criterion for the amendment, deletion or addition of some paragraphs, which were 28 in their final form. Construction Validity Indicators were also measured by conducting a pilot study on a sample of 40 students from a similar population. The research tool was applied and the correlation coefficient between the paragraphs was calculated with the total score. The paragraphs of the scale were analyzed and the coefficient of discrimination of each paragraph was calculated. The coefficient of discrimination here represents an indicator of validity for each paragraph in the form of a correlation coefficient between each paragraph and its relation to the dimension to which it measures $0.402-0.854$, and this is shown in Table 2. 
Table 2. Correlations between paragraphs and dimensions on the metacognitive thinking scale

\begin{tabular}{llll}
\hline Paragraph & Correlation coefficient to the total score & Paragraph & Correlation coefficient to the total score \\
\hline 1 & ${ }^{* *} 0.603$ & 15 & $* * 0.809$ \\
2 & ${ }^{* *} 0.796$ & 16 & $* * 0.737$ \\
3 & $* * 0.844$ & 17 & $* * 0.831$ \\
4 & $* * 0.549$ & 18 & $* * 0.633$ \\
5 & $* * 0.795$ & 19 & $* * 0.515$ \\
6 & $* * 0.846$ & 20 & $* * 0.843$ \\
7 & $* 0.672$ & 21 & $* * 0.535$ \\
8 & $* * 0.823$ & 22 & $* * 0.752$ \\
9 & $* * 0.534$ & 23 & $* * 0.852$ \\
10 & $* * 0.823$ & 24 & $* * 0.608$ \\
11 & $* * 0.739$ & 25 & $* * 0.853$ \\
12 & $* 0.789$ & 26 & $* * 0.744$ \\
13 & $* * 0.858$ & 27 & $* * 0.725$ \\
14 & $* * 0.687$ & 28 & $* * 0.619$ \\
\hline
\end{tabular}

Note. $* *$ Statistically significant at $(0.01)$.

Table 2 shows that all correlation coefficients were acceptable and statistically significant at 0.01 . As a result, none of the paragraphs were deleted.

\subsection{Reliability}

To ensure the reliability of the scale, the test-retest method was used by applying it to a sample of 30 learning disabilities students and a two-week interval between the first and second applications. The correlation coefficient in the regression method as a whole was 0.826 . Stability coefficient was calculated by using the Cronbach Alpha. The stability coefficient according to the internal consistency of the scale as a whole was 0.845 , indicating that the scale has an appropriate level of stability as shown in Table 3.

Table 3. Cronbach Alpha of correlation coefficient

\begin{tabular}{ll}
\hline Method & Correlation coefficient \\
\hline test-retest & 0.826 \\
Cronbach Alpha & 0.845 \\
\hline
\end{tabular}

Based on the methods used to indicate the validity and reliability of the scale, it was clear that the scale was valid and appropriate for the current study. The questionnaire consisted from 28 paragraphs in its final form. The answers to the questionnaire were based on Five-Likert point scale: always (5) degrees, often (4) degrees, sometimes (3) degrees, rarely (2) degrees, and not at all (1) degree. the levels of metacognition among students was divided according to the following criteria: From (1-2.33) low level of metacognitive thinking, from (2.343.67) the medium level of meta-cognitive thinking, from (3.68-5) high level of meta-cognitive thinking.

\section{Results}

\subsection{First, the Results Related to the First Question}

This section tends to give answers to the first research question: "What is the level of metacognitive thinking among learning disabilities students in Asir Area?" To answer this question, the mean scores and standard deviations of the level of metacognitive thinking among students with learning difficulties in the basic stage in Asir Area was calculated as shown in Table 4. 
Table 4. The mean scores and standard deviations of the level of metacognitive thinking among students with learning disabilities

\begin{tabular}{|c|c|c|c|c|}
\hline Number & Paragraph & Mean Score & $\mathrm{SD}$ & Level \\
\hline 26 & The students learn more when interested in the subject & 2.47 & 0.621 & Average \\
\hline 10 & His attention focuses on valuable and important information & 2.39 & 0.611 & Average \\
\hline 3 & He slows down when making the decision to give himself enough time & 2.34 & 0.678 & Average \\
\hline 21 & He tries to formulate the new knowledge with his own words & 2.29 & 0.598 & Low \\
\hline 7 & He slows down a bit when facing important information & 2.23 & 0.632 & Low \\
\hline 24 & He reads the instructions carefully before starting the task & 2.18 & 0.485 & Low \\
\hline 14 & He thinks of multiple ways to solve the problem and choose the best & 2.17 & 0.594 & Low \\
\hline 19 & He assesses his understanding of things very well & 2.11 & 0.684 & Low \\
\hline 6 & He sets specific goals before starting the task & 1.96 & 0.523 & Low \\
\hline 25 & He reassesses his assumptions when he gets confused & 1.89 & 0.543 & Low \\
\hline 12 & He uses a variety of strategies depending on the situation & 1.83 & 0.873 & Low \\
\hline 16 & He uses his mental abilities to compensate for his weaknesses & 1.76 & 0.611 & Low \\
\hline 1 & He considers several alternatives to solve the problem before answering & 1.72 & 0.621 & Low \\
\hline 28 & He stops and re-reads when he finds himself confused & 1.62 & 0.654 & Low \\
\hline 15 & He summarizes what he did after completing the task & 1.61 & 0.598 & Low \\
\hline 8 & He knows what type of information is important for decision-making & 1.57 & 0.608 & Low \\
\hline 4 & He understands the strengths and weaknesses of his mental abilities & 1.54 & 0.572 & Low \\
\hline 17 & He focuses on the meaning and importance of new information & 1.44 & 0.592 & Low \\
\hline 5 & He thinks about what he needs to learn before he starts a task & 1.43 & 0.631 & Low \\
\hline 13 & He has a good control capacity in making decisions & 1.37 & 0.725 & Low \\
\hline 11 & He has a specific goal for each strategy he uses & 1.33 & 0.963 & Low \\
\hline 9 & He can organize information well & 1.23 & 0.582 & Low \\
\hline 20 & Useful strategies are used on time & 1.22 & 0.560 & Low \\
\hline 23 & The information is used systematically to help solve the problem & 1.19 & 0.685 & Low \\
\hline 18 & Putting examples on his own to make the information meaningful & 1.16 & 0.622 & Low \\
\hline 27 & He tries to defragment work into small tasks for easy handling & 1.14 & 0.486 & Low \\
\hline 22 & He changes his strategies when he can not understand the subject well & 1.11 & 0.702 & Low \\
\hline \multirow[t]{2}{*}{2} & Trying to use proven strategies in the past & 1.09 & 0.632 & Low \\
\hline & total score & 1.69 & 0.331 & Low \\
\hline
\end{tabular}

Table 4 shows that respondents have a low level of meta-cognitive thinking, with a mean score of 1.69 and a standard deviation of 0.331 .

\subsection{Second, the Results Related to the Second Question}

This section presents the findings obtained to answer the second research question: "Does the level of metacognitive thinking of learning disabilities students differ on the scale used, depending on age, grade, and type of difficulty?"

In order to answer this question, the mean scores and the standard deviations of the students' scores were calculated according the scale of metacognitive thinking and according to the variables as shown in Table 5.

Table 5. The mean scores and the standard deviations of the students' metacognitive thinking according to the variables of age, grade, and type of difficulty

\begin{tabular}{llll}
\hline Variable & Category & Mean Score & Standard Deviation \\
Age & 8 & 1.75 & 0.392 \\
& 9 & 1.65 & 0.406 \\
Grade & 10 & 1.70 & 0.384 \\
& 11 & 1.66 & 0.365 \\
& third & 1.68 & 0.363 \\
Type of difficulty & fourth & 1.75 & 0.352 \\
& Fifth & 1.65 & 0.387 \\
& Sixth & 1.68 & 0.395 \\
& Reading & 1.71 & 0.403 \\
& Writing & 1.67 & 0.392 \\
& Maths & 1.69 & 0.377 \\
\hline
\end{tabular}


Table 5 shows that there were clear differences between the mean scores of the students on the metacognitive thinking scale according to the study variables, and to identify the significance of these differences, 3-Way ANOVA was used as shown in Table 6.

Table 6. 3-Way ANOVA results for the differences between the mean scores in the metacognitive thinking scale according to the variables

\begin{tabular}{llllll}
\hline Variable & Total squares & DF & sum of squares & F value & Sig. \\
\hline Age & 0.265 & 3 & 0.088 & 0.536 & 0.658 \\
Grade & 1.018 & 3 & 0.339 & 2.062 & 0.105 \\
Type & 0.865 & 2 & 0.433 & 2.630 & 0.074 \\
Error & 56.086 & 341 & 0.164 & & \\
Total & 1865.187 & 350 & & & \\
\hline
\end{tabular}

The above table shows that the values of significance levels were greater than 0.05 for all variables, indicating that there were no statistically significant differences between the mean scores of students on the cognitive thinking scale due to age, class or difficulty type.

\section{Discussion}

The results of the study revealed a low level of metacognitive thinking among the sample of the study. The average mean score was 1.69 , which may be as a result of the nature of traditional teaching methods, the lack of readiness of learning disabilities rooms, and the lack of modern methods used in the learning process that may help people with learning difficulties to use cognitive thinking skills. This result can be attributed also to the absence of instructional strategies that help to use metacognitive thinking and limiting the teaching process to traditional strategies. For example, students are not assigned periodic visits to the library to search books, scientific journals and the Internet. These visits may help in increasing awareness among LD students of their abilities, which may contribute to the transition from cognition to metacognition. These findings are inconsistent with previous studies (Alsalem, 2018), which revealed a high level of metacognitive skills of LD students. These findings agree with other studies (Al-Dokhi, Al-Yousif, \& Al-Atara, 2016), which revealed LD students have low levels of metacognitive thinking skills. As for the second question, the results indicated that there are no statistically significant differences between the mean scores of students on the metacognitive thinking scale due to age, grade or type of difficulty. This study did not agree or differ with the previous studies. This result is due to the difficulties of metacognition and memory is common characteristics of people with learning disabilities, which led to the absence of differences in the metacognitive skills regardless of age, grade and type of difficulty.

\section{Conclusion}

The above findings show that the levels of metacognitive thinking among the sample of this study was low indicating less developed rooms specialized for students with learning disabilities. The role of these special rooms is of great importance as they nurture and support their needs and help in enhancing their metacognitive skills. The current strategies used by teachers are not tailored to the real needs of this type of students or even to help in developing metacognitive thinking skills. From the findings of the study, we recommend the following:

1) Preparing rooms for learning difficulties and qualifying and providing them with the latest teaching methods that help LD students acquire metacognitive thinking skills.

2) The need to train and prepare teachers of learning disabilities on how to provide students with the metacognitive thinking skills through curriculum, extra materials, courses and programs.

3) Future studies could examine the relationship between metacognitive thinking and other variables such as psychological compatibility and self-efficiency.

\section{Acknowledgment}

This study was sponsored by the Research Group Program of the Scientific Deanship at King Khalid University, Kingdom of Saudi Arabia (R.G.P.IL105L40).

\section{References}

Abu Issa, S. (2016). The impact of the strategy of mapping maps on the development of the achievement and skills of knowledge of the subject of science in primary school students. Journal of the Faculty of Education in Port Said, 20, 543-569. 
Al-Dokhi, F., Al-Yousif, H., \& Al-Atara, M. (2016). The effectiveness of a training program based on the development of the awareness of the meta-knowledge strategies in increasing the educational achievement of students with learning disabilities. Educational Magazine - Kuwait, 30(119), 61-100.

Al-Faramawi, H., \& Hassan, W. (2004). Meta-Knowledge, Between Theory and Research. Cairo: Anglo-Egyptian Library.

Alenizi, M. A. K., \& Alanazi, M. S. (2016). The Effectiveness of Metacognitive Teaching Strategies to Enhance Elementary School Pupils' Reading Skills in the Northern Border Areas of Saudi Arabia. International Journal of English Linguistics, 6(4), 213-226. https://doi.org/10.5539/ijel.v6n4p213

Alsalem, M. A. (2018). Exploring metacognitive strategies utilizing digital books: Enhancing reading comprehension among deaf and hard of hearing students in Saudi Arabian higher education settings. Journal of Educational Computing Research, 56(5), 645-674. https://doi.org/10.1177/0735633117718226

Cross, D. R., \& Paris, S. G. (1988). Developmental and instructional analyses of children's metacognition and reading comprehension. Journal of Educational Psychology, $80(2), \quad 131$. https://doi.org/10.1037/0022-0663.80.2.131

Esmaili, S. K., Shafaroodi, N., Mehraban, A. H., Parand, A., Zarei, M., \& Akbari-Zardkhaneh, S. (2017). Effect of play-based therapy on meta-cognitive and behavioral aspects of executive function: a randomized, controlled, clinical trial on the students with learning disabilities. Basic and Clinical Neuroscience, 8(3), 203. https://doi.org/10.18869/nirp.ben.8.3.203

Farhan, D. (2003). The effect of using cognitive and metacognitive strategy on improving the performance of a sample of students with learning difficulties in solving the verbal mathematical problem. Unpublished Master Thesis, University of Jordan: Jordan.

Flavell, J. H. (1979). Metacognition and cognitive monitoring: A new area of cognitive-developmental inquiry. American Psychologist, 34(10), 906. https://doi.org/10.1037/0003-066X.34.10.906

Girli, A., \& Öztürk, H. (2017). Metacognitive Reading Strategies in Learning Disability: Relations between Usage Level, Academic Self-Efficacy and Self-Concept. International Electronic Journal of Elementary Education, 10(1), 93-102. https://doi.org/10.26822/iejee.2017131890

Hennessey, M. G. (1999). Probing the Dimensions of Metacognition: Implications for Conceptual Change Teaching-Learning.

Khasawneh, M. A. (2016). Introduction to learning difficulties (arbitrator and evaluator scientifically). Amman: Dar Al-Fikr Publishers and distributors.

Kudo, M. F., Lussier, C. M., \& Swanson, H. L. (2015). Reading disabilities in children: A selective meta-analysis of the cognitive literature. Research in Developmental Disabilities, 40, 51-62. https://doi.org/10.1016/j.ridd.2015.01.002

Paris, S. G., \& Winograd, P. (1990). Promoting metacognition and motivation of exceptional children. Remedial and Special Education, 11(6), 7-15. https://doi.org/10.1177/074193259001100604

Peijnenborgh, J. C., Hurks, P. M., Aldenkamp, A. P., Vles, J. S., \& Hendriksen, J. G. (2016). Efficacy of working memory training in children and adolescents with learning disabilities: A review study and meta-analysis. Neuropsychological Rehabilitation, 26(5-6), 645-672. https://doi.org/10.1080/09602011.2015.1026356

Schraw, G., \& Moshman, D. (1995). Metacognitive theories. Educational Psychology Review, 7(4), 351-371. https://doi.org/10.1007/BF02212307

Vaidya, S. R. (1999). Metacognitive learning strategies for students with learning disabilities. Education, 120(1), $186-186$.

Wiens, J. W. (1983). Metacognition and the adolescent passive learner. Journal of Learning Disabilities, 16(3), 144-149. https://doi.org/10.1177/002221948301600302

\section{Copyrights}

Copyright for this article is retained by the author, with first publication rights granted to the journal.

This is an open-access article distributed under the terms and conditions of the Creative Commons Attribution license (http://creativecommons.org/licenses/by/4.0/). 